\title{
Utilização de vagens de Prosopis juliflora na alimentação de bovinos e equinos ${ }^{1}$
}

\author{
Marcia A. Medeiros ${ }^{2}$, Franklin Riet-Correa², André F.A. Pessoa ${ }^{2}$, Clarice R.M. Pessoa², Jouberdan \\ A. Batista, Antônio F.M. Dantas ${ }^{2}$, Eldinê G. Miranda Neto ${ }^{2}$ e Rosane M.T. Medeiros ${ }^{2 *}$
}

\begin{abstract}
Medeiros M.A., Riet-Correa F., Pessoa A.F.A., Pessoa M.C.R., Batista J.A., Dantas A.F.M., Miranda Neto E.G. \& Medeiros R.M.T. 2012. [Use of Prosopis juliflora pods as food for cattle and horses.] Utilização de vagens de Prosopis juliflora na alimentação de ruminantes e equinos. Pesquisa Veterinária Brasileira 32(10):1014-1016. Hospital Veterinário, Centro de Saúde e Tecnologia Rural, Universidade Federal de Campina Grande, Campus de Patos, PB 58708-110, Brazil. E-mail: rmtmed@uol.com

The ingestion of pods of Prosopis juliflora causes nervous signs in cattle due to lesions in the trigeminal nuclei, and colics in horses due to the formation of phytobezoars in the gut. The objective of this research was to study the toxicity for of P. juliflora pods in horses, and to establish if $30 \%$ of pods in the feed are not toxic for cattle. Three experiments were performed. In Experiment 1, two steers were fed, during one year, with food containing 30\% of $P$. juliflora pods. None of the experimental animals showed nervous signs. In Experiment 2 , two horses received pods of $P$. juliflora in amount equivalent to $1 \%$ of their bw during four months. For other 3 months this amount was increased to $1.5 \%$ bw. In Experiment 3, two horses received P. juliflora pods ad libitum during 30 days. None of the horses showed nervous signs or colic due to the presence of phytobezoars in the gut. These results suggest that $P$. juliflora pods, despite their toxicity, can be used to feed cattle at concentrations of $30 \%$ of the food during one year. There are no restrictions for the use of P. juliflora pods in horses in confined or semi-confined systems, but it is not recommended to maintain equidae grazing in areas where P. juliflora is fructificating. It is suggested that there is a loss in the capacity of the pods to form phytobezoars after harvesting. Cattle may be kept in areas invaded by $P$. juliflora, during fructification, for no more than 30 days.
\end{abstract}

INDEX TERMS: Prosopis juliflora, toxicity, nervous signs, phytobezoars. cattle, equidae.

RESUMO.- As vagens de Prosopis juliflora (algaroba) causam sinais nervosos em bovinos, devidos a lesões no núcleo motor do trigêmeo, e cólicas em cavalos devidos à formação de fitobezoários no intestino. 0 presente trabalho objetivou estudar a toxicidade das vagens de $P$. juliflora para equinos e comprovar que a utilização $30 \%$ de vagens adicionadas na ração de bovinos não causa intoxicação. Para isso foram realizados três experimentos. No Experimento 1 , dois bovinos ingeriram, durante um ano, vagens de algaroba, em quantidade equivalente a $30 \%$ do total da matéria

\footnotetext{
${ }^{1}$ Recebido em 4 de junho de 2012.

Aceito para publicação em 10 de julho de 2012.

Parte da Dissertação de Mestrado do primeiro autor, no Programa de Pós-Graduação em Medicina Veterinária, Universidade Federal de Campina Grande (UFCG), Av. Universitária s/n, Bairro Santa Cecília, Patos, PB 58708-110, Brasil.

${ }^{2}$ Hospital Veterinário, Centro de Saúde e Tecnologia Rural (CSTR), UFCG, Patos, PB. *Autor para correspondência: rmtmed@uol.com
}

seca ingerida. Nenhum animal experimental apresentou sinais nervosos. No Experimento 2, dois cavalos receberam vagens em quantidade equivalente a $1 \%$ do peso corporal (pc) durante quatro meses e em quantidade equivalente a $1,5 \%$ do pc durante outros três meses. No experimento 3 , dois equinos receberam vagens ad libitum, durante um mês. Em nenhum dos equinos foram observados sinais nervosos nem cólicas devidas à formação de fitobezoários. Esses resultados sugerem que as vagens de algoraba, apesar de sua toxicidade, podem ser utilizadas na alimentação de bovinos em confinamento ou semi-confinamento, nas concentrações de $30 \%$ da alimentação por períodos de até um ano. Não há restrições para a administração de vagens de algaroba em equinos confinados; no entanto, permanecem as restrições para o pastejo de equídeos em áreas invadidas por algaroba. Sugere-se que as vagens perdem a sua capacidade de formar fitobezoários em consequência do armazenamento. Bovinos não devem permanecer em áreas 
invadidas por P. juliflora, quando a planta está frutificando, por mais de 30 dias.

TERMOS DE INDEXAÇÃO: Prosopis juliflora, toxicidade, sinais nervosos, fitobezoários. bovinos, equinos.

\section{INTRODUÇÃO}

A intoxicação por vagens de Prosopis juliflora (algaroba) tem sido descrita em bovinos (Dantas 1996, Silva et al. 2006, Tabosa et al. 2006, Câmara et al. 2009) causando um quadro clínico de disfunção de nervos cranianos, principalmente do núcleo motor do trigêmeo. A doença foi reproduzida experimentalmente em bovinos que ingeriram vagens ou farelo de algaroba constituindo $50 \%-100 \%$ da alimentação após um período de 45-110 dias (Tabosa et al. 2006).

Nunca foram observados sinais nervosos em equídeos associados à ingestão de vagens de P. juliflora. No entanto, em equinos, a ingestão de vagens de algaroba tem sido associada à cólica causada por fitobezoarios no intestino. Dois equinos apresentaram cólica obstrutiva não-estrangulante moderada após ter acesso a uma área invadida por algaroba, com grande quantidade de vagens no chão. Os animais foram submetidos a laparotomia exploratória com acesso ventral, resultando em retirada de fitobezoários formados por sementes e vagens de algaroba (Pessoa et al. 2012).

Considerando que as vagens de algaroba são uma boa alternativa para a alimentação de herbívoros no semiárido, tanto administradas como concentrado, quanto como consumidas diretamente pelos animais no campo durante a sementação, o presente trabalho teve como objetivos estudar a toxicidade de vagens de $P$. juliflora em equinos e avaliar se a utilização $30 \%$ de vagens na ração de bovinos causa intoxicação.

\section{MATERIAL E MÉTODOS}

Neste trabalho foram realizados três experimentos, sendo um em bovinos e dois em equinos. Todos os experimentos foram realizados nas dependências do Hospital Veterinário (HV) do Centro de Saúde e Tecnologia Rural (CSTR), Universidade Federal de Campina (UFCG), Campus de Patos, PB.

Experimento 1: Determinação de doses não tóxicas de Prosopis juliflora na alimentação de bovinos

Para este experimento foram utilizados dois bovinos machos, cruzas zebuínos, pesando em média $130 \mathrm{~kg}$, que foram alimentados, diariamente, por um período de 12 meses, com uma dieta de vagens de algaroba na proporção de $30 \%$ do total da matéria seca ingerida [estimada em $2 \%$ do peso corporal (pc)], $0,5 \%$ do pc de farelo de milho, e feno de capim tifton e água à vontade. A matéria seca das vagens de algaroba foi de $78,4 \%$. Os animais eram pesados mensalmente para reajuste de dieta e alojados em currais separados.

Mensalmente, durante um ano, foi realizado o exame clínico do sistema nervoso, utilizando como controle um bovino sem sinais nervosos. Após esse período os animais foram abatidos para consumo sendo coletado o encéfalo, a medula espinhal e os músculos masseteres que foram fixados em solução tamponada de formol a 10\% para estudo histológico. Posteriormente foram realizados cortes transversais do sistema nervoso central abrangendo cortes do córtex frontal, occipital e parietal, tálamo, mesencéfalo, núcleos da base, cerebelo, bulbo, ponte, hipocampo, gânglio trigêmeo e hipófise e medula espinhal cervical, torácica e lombar. Em seguida, as amostras do sistema nervoso e dos músculos masseteres foram incluídos em parafina, cortados com uma espessura de 5 micrômetros e corados pela técnica de Hematoxilina-Eosina.

\section{Experimentos 2 e 3: Toxicidade de vagens de $P$. juliflora em} equinos

No Experimento 5 utilizaram-se quatro equinos, machos, castrados, com idade variando de quatro à 14 anos, pesando 240-360 $\mathrm{kg}$, que foram vermifugados e alocados em baias individuais. Dois animais receberam vagens de algaroba como concentrado e dois foram mantidos como grupo controle, recebendo ração comercial na mesma proporção. 0 grupo experimental recebeu as vagens em quantidade equivalente a $1 \%$ do pc durante quatro meses, sendo que nas duas primeiras semanas os animais receberam 0,5\% e 0,75\% do pc. Quatro meses após o início da administração, a quantidade de vagens oferecida foi aumentada para $1,5 \%$ do pc e os animais ingeriram as vagens por mais três meses.

No Experimento 6, dois equinos receberam uma dieta de vagens de algaroba ad libitum durante um mês.

Nos dois experimentos todos os equinos receberam feno de capim tifton (Cynodon dactylon) como volumoso e água ad libitum.

\section{RESULTADOS}

\section{Experimento 1}

Não foram observados sinais clínicos em nenhum dos dois animais experimentais. 0 Bovino 1 , com um peso inicial de $132 \mathrm{~kg}$, pesava no final de experimento $381 \mathrm{~kg}$, o que representa um ganho de peso médio mensal de $20 \mathrm{~kg}$ e o Bovino 2, com peso inicial de $116 \mathrm{~kg}$, apresentou no final do experimento $333 \mathrm{~kg}$, representando um ganho de peso mensal de $18 \mathrm{~kg}$. No estudo histológico não foram observadas lesões do sistema nervoso nem dos músculos masseteres.

\section{Experimentos 2 e 3}

No Experimento 2, um animal apresentou cólicas espasmódicas intermitentes após 141 dias de ingestão das vagens. Foi submetido a laparotomia exploratória mas pela palpação dos segmentos intestinais não foram verificadas fitobezoarios. Após a laparotomia, realizada no final do experimento (sete meses) o animal deixou de ingerir algaroba e não apresentou mais cólicas. Os demais animais não apresentaram nenhum sinal clínico.

Durante os quatro meses que os animais ingeriram quantidade de vagens equivalentes a $1 \%$ do pc não se registraram sobras. Nos três meses que receberam vagens em quantidade equivalente a $1,5 \%$ do pc verificaram-se sobras equivalentes a 0,1 à $0,4 \%$ do pc.

No Experimento 3 nenhum dos dois animais que receberam vagens de algaroba ad libitum durante um mês apresentou cólica. 0 consumo médio diário foi de 1,1\% a 1,4\% do pc.

\section{DISCUSSÃO E CONCLUSÕES}

Os resultados do Experimento 1 sugerem que os bovinos podem ser alimentados com vagens de algaroba em quantidades equivalente a $30 \%$ da matéria seca ingerida por períodos de até um ano. É interessante ressaltar que em 
bovinos, pelo menos após a identificação da toxicidade das vagens de algaroba (Figueiredo et al. 1995), as intoxicações por algaroba têm sido diagnosticada exclusivamente em bovinos que ingerem as vagens a campo, em áreas invadidas por algaroba. Neste aspecto seria importante, sempre que possível, colher as vagens de algaroba e ministrar as mesmas aos bovinos em concentrações não tóxicas. Por outro lado, a moagem da algoraba ("farelo" de algaroba), apesar de manter a toxicidade (Tabosa et al. 2006), é uma boa alternativa para evitar a difusão da planta através de sementes ingeridas no campo pelo animais e eliminadas pelas fezes. A alimentação com vagens de algaroba no campo não é recomendada na alimentação de bovinos, a não ser por períodos curtos, de até 30 dias.

Nos experimentos 2 e 3 foi comprovado que a administração das vagens não causa sinais nervosos nem formação de fitobezoários em cavalos. No entanto, fitobezoários formados por vagens e sementes de algaroba têm sido encontrados, como causa de cólica, em cavalos pastejando em áreas invadidas por algaroba (Pessoa et al. 2012). Esse fato sugere que a falha na reprodução experimental dos fitobezoários seja devida a diferentes características das vagens de algaroba quando recém caem das árvores se comparadas com as que foram utilizadas neste experimento, que, no início do mesmo tinham sido armazenadas por 6 meses. Provavelmente o armazenamento, pela dessecação ou pela presença de insetos parasitas, causa mudanças na estrutura das vagens diminuindo as possibilidades de formar fi- tobezoarios. Neste aspecto alguns produtores mencionam que as cólicas causadas pela ingestão de vagens de $P$. juliflora, a campo, só ocorrem quando os equinos ingerem as vagens úmidas, após a ocorrência de chuvas.

Agradecimentos.- Trabalho financiado pelo Instituto Nacional de Ciência e Tecnologia para o Controle das Intoxicações por Plantas (CNPq, Proc. 573534/2008-0).

\section{REFERÊNCIAS}

Dantas J.R.F. 1996. UFPB, UFBA e USP estudam “cara torta”, doença que acomete bovinos na Paraíba, Pernambuco e Rio Grande do Norte. Revta Criadores 46:32.

Câmara A.C.L., Costa N.A., Riet-Correa F., Afonso J.A.B., Dantas A.F.M., Mendonça C.L. \& Souza M.I. 2009. Intoxicação espontânea por vagens de Prosopis juliflora (Leg. Mimosoideae) em bovinos em Pernambuco. Pesq. Vet. Bras. 29(3):233-240.

Figueiredo L.J.C., Ferreira M.M., Távora J.P.F., Dantas J. \& Simões S.D. 1995. Estudo clínico e anatomopatológico da doença "cara torta" em bovinos no nordeste brasileiro. Arq. Med. Vet. UFBA 18:175-183.

Pessoa A.F.A., Miranda Neto E.G., Pessoa C.R.M., Simões S.V.D., Azevedo S.S. \& Riet-Correa F. 2012. Cólica em equídeos no semiárido do Nordeste do Brasil. Pesq. Vet. Bras. 32(6):503-509.

Silva D.M., Riet-Correa F., Medeiros R.M.T. \& Oliveira O.D. 2006. Plantas tóxicas para ruminantes e eqüídeos no Seridó Ocidental e Oriental do Rio Grande do Norte. Pesq. Vet. Bras. 26(4):223-236.

Tabosa I.M., Riet-Correa F., Barros S.S., Summers B.A., Simões S.V.D., Medeiros R.M.T. \& Nobre V.M.T. 2006. Neurohistologic and ultrastructural lesions in cattle experimentally intoxicated with the plant Prosopis juliflora. Vet. Pathol. 43:695-701. 